care if the family is not to be placed under intolerable strain. Particular emphasis is given to the importance and effectiveness of support groups for relatives in giving relief to caregivers upon discovering that their feelings of anger, sadness, guilt, and fear were also experienced by others, and in sharing practical solutions to problems of caring.

\title{
GOMMENT
}

Social workers are frequently not good at communicating in terms others can understand what their contribution to the resolution of social problems can be. This paper is a refreshing distillation of 'practice wisdom' in a very readable style which clearly relates different service responses to the typical stages through which a family with a member with dementia will pass. It is only to be hoped that practitioners will find their work situation allows such a sensitive service to evolve.

Social Work Services Group

Edinburgh

\section{Psychology and Psychiatry}

\section{Jeffrey Garland}

Linda Powell-Procton and Edgar Miller, 'Reality Orientation:

A Critical Appraisal', British Journal of Psychiatry, 1982, 140, pp. $457-463$.

What is 'RO'? A transcendental password whispered by a guru? A warning that only your best friend should hiss? Neither - yet both seems to be the verdict of this Cambridge paper which adds to the growing number of question marks poised over reality orientation, a fashionable philosophy of care for old people in institutions.

The authors agree that $\mathrm{RO}$ is unique in being a widely accepted approach specially designed for mentally frail old people, and that care staff trained persistently to cue and prompt residents to use correct information on time, place and person are more likely to interact positively and to find their work more rewarding.

However, they also assert that $\mathrm{RO}$, like a mantra, does have an element of mystique, is not well thought out and appears somewhat vague and woolly. While they do not come right out with it and say that RO actually smells, they wrinkle their noses in a pained way and leave us to draw our own, not very difficult, conclusions.

Essentially, Powell-Proctor and Miller argue, RO is a signpost which has been mistaken for the desired destination. We should, they urge, be 
working on interventions closely tailored to the needs of individuals, "to analyse the nature of behavioural impairments and to design intervention programmes directed towards maximizing the individual's overall adaptation and independence' (p. 462). RO, in contrast, is a non-specific modification to the institutional environment. It shows good intentions but as an end in itself it would be dangerously misleading.

The case is a telling one. It was made three years ago by Schwenk in a paper not cited by these authors, ${ }^{1}$ but is none the worse for being made again. The $\mathrm{RO}$ bandwagon is still rolling, with the first British book on the subject now out, ${ }^{2}$ and much clinical and research effort is being expended on this approach in spite of its uncertain status and mediocre record.

Is $\mathrm{RO}$ to be seen as a course of treatment, a therapy that can be evaluated in controlled studies? Many practitioners deny that this is the case, likening it to a prosthetic aid that maintains functioning (both for residents and for staff!) but which cannot be removed without corresponding deterioration. To prescribe and provide an aid is a component of treatment but is not a therapy in itself that can be evaluated against other therapies or no-treatment controls. $\mathrm{RO}$ in this view is a cluster of attitudes and preferred methods of communication - a frame of reference rather than a therapy.

It is unfortunate that Powell-Proctor and Miller miss this point, and throughout their paper analyse RO as a therapy. They can be excused for doing this, as a number of practitioners seem most uncertain about the status of what they are doing and have, by accident or design, taken a stance which encourages others to view them as therapists.

We need to bear in mind that $\mathrm{RO}$, once in action, needs to go on for ever if its effectiveness is to be maintained. Even for the ardent practitioner it is physically and mentally draining. For many residents it can be extremely aversive, necessarily confronting them with their repeated failures in understanding. For para-professional staff without direct investment in the procedure the temptation to dilute contacts into everyday chat, with the rationalization that everything is $\mathrm{RO}$ really, can be overwhelming.

Such important issues are seldom addressed, and have been skirted by these authors. Nevertheless, their paper is a valuable attempt to inject clear thinking into an area of practice not noted for this quality. It should become required reading for all those seriously interested in the reality of work with mentally impaired old people.

Oxford D.H.A. 
NOTES

I Schwenk, M. A., Reality Orientation for the Institutionalized Aged: Does It Help? The Gerontologist, 1979, 19, 373-7.

2 Holden, U. P. and Woods, R. T., Reality Orientation. Psychological Approaches to the 'Confused' Elderly, Churchill Livingstone, 1982.

\section{Epidemiology and Community Medicine}

\section{John Bond}

K. G. Manton, Changing concepts of morbidity and mortality in the elderly population. Milbank Memorial Fund Quarterly/Health and Society, 60 ( 1982$)$, I $83-244$.

In the previous edition of Ageing and Society Bromley, Isaacs and Bytheway ${ }^{1}$ reviewed the important book by Fries and $\mathrm{Crapo}^{2}$ in which they developed a theory of ageing describing the human survival curve as approximately rectangular. The reviewers were not entirely complimentary to the Fries and Crapo thesis and in this lengthy article Manton continues the attack, showing that the rectangular survival curve theory and other existing models and theories of human mortality are inconsistent with national mortality and morbidity data.

Mortality is both a public issue ${ }^{3}$ and a private trouble. ${ }^{4}$ For society mortality is a major factor in determining the age structure of the population, knowledge of which is essential in planning health and welfare services. To the individual mortality determines the number of years of life that a person can expect to live, which will influence the way he or she plans a career, retirement and investment goals. The importance and interest surrounding theories of human ageing cannot therefore be under-estimated. This article reviews such theories; examines them in the light of our perception of both the quantitative and qualitative aspects of human ageing; and suggests an agenda for future epidemiological research into the nature and implications of current mortality patterns in the U.S.A.

Current theories of human ageing predict that life expectancy is unlikely to increase much beyond present levels. Two explanations have been proposed. The first suggests that the limitation on life span is due to the cellular processes of senescence and the second suggests that there is increased societal risk of mortality from chronic diseases.

Manton highlights four types of evidence put forward to support the view that senescence will soon limit life expectancy. First, historically, the maximum human life span has not been observed to change except 